\title{
HUBUNGAN PERBEDAAN KERAPATAN LAMUN DENGAN KELIMPAHAN EPIFAUNA DI PANTAI LIPI, PULAU PARI, KEPULAUAN SERIBU
}

The relations between Seagrass Density and the Abundance of Epifauna at the Coast of Lipi, Pari, Seribu Island

\author{
Kartika Putri Kusumaatmaja, Siti Rudiyanti *), Churun 'Ain
}

Program Studi Manajemen Sumberdaya Perairan, Departemen Sumberdaya Akuatik

Fakultas Perikanan dan Ilmu Kelautan, Universitas Diponegoro

Jl. Prof. Soedarto, SH, Tembalang, Semarang, Jawa Tengah - 50275, Telp/Fax +6224 7474698

Email :kartikakus@gmail.com

\begin{abstract}
ABSTRAK
Pulau Pari merupakan kawasan perairan yang memiliki ekosistem lamun.Ekosistem ini merupakan salah satu habitat yang mendukung kehidupan biota akuatik, salah satunya epifauna.Ekosistem ini digunakan sebagai tempat mencari makan bagi epifauna dengan memanfaatkan serasah daun lamun.Adanya perbedaan tingkat kerapatan lamun dapat memberikan pengaruh terhadap kelimpahan epifauna.Penelitian ini bertujuan untuk mengetahui jenis lamun, kelimpahan epifauna pada kerapatan lamun yang berbeda, dan keeratan hubungan antara kerapatan lamun dengan kelimpahan epifauna.Kegiatan penelitian ini dilaksanakan pada bulan Mei-Juni 2016.Metode yang digunakan adalah metode survei dengan penentuan titik sampling menggunakan metode purposive sampling yaitu pembagian stasiun sampling berdasarkan perbedaan kerapatan lamun (padat, sedang dan jarang).Pengambilan sampel epifauna dilakukan secara manual menggunakan tangan setiap satu minggu sekali selama 3 minggu. Hasil yang diperoleh yaitu terdapat tiga jenis lamun diantaranya Thalassia sp., Enhalus sp. dan Cymodocea sp. Pada kerapatan padat (stasiun A) dengan jumlah tegakan 399 ind $/ \mathrm{m}^{2}$ memiliki kelimpahan epifauna $121 \mathrm{ind} / \mathrm{m}^{2}$, kerapatan sedang (stasiun B) dengan jumlah tegakan $333 \mathrm{ind} / \mathrm{m}^{2}$ memiliki kelimpahan epifauna sebanyak $93 \mathrm{ind} / \mathrm{m}^{2}$, dan pada kerapatan jarang (stasiun C) dengan jumlah tegakan 308 ind $/ \mathrm{m}^{2}$, memiliki kelimpahan epifauna sebanyak $67 \mathrm{ind} / \mathrm{m}^{2}$. Hubungan antara kerapatan lamun dengan kelimpahan epifauna mendapatkan koefisien korelasi sebesar $\mathrm{r}=0,949$ dengan nilai $\alpha<0,05$ menandakan adanya keeratan hubungan yangpositif dan kuat.
\end{abstract}

Kata Kunci : Ekosistem Lamun, Kelimpahan Epifauna, Pulau Pari.

\section{ABSTRACT}

Pari Island is an area of ocean waters that have a seagrass ecosystem. This ecosystem is one of the habitats that support life of aquatic organism, which is epifauna. This ecosystem is used for feeding grounds for epifauna by utilizing the seagrass leaf litter. Difference of seagrass species density can influence abundance of epifauna. This research aims to determine the seagrass species, the abundance of epifauna in different seagrass densities, and the relationship between seagrass density with the abundance of epifauna. The research activities conducted in May-June 2016. The method used is survey method in determining the point of sampling using purposive sampling method namely the allocation of sampling stations based on different seagrass density (dense, medium and rare. The sampling of epifauna was done manually using hand every once a week for 3 weeks. The results obtained that there are three species of seagrass including Thalassia sp, Enhalus sp and Cymodocea sp. The densities in dense seagrass (station A) by the number of stands 399 ind $/ \mathrm{m}^{2}$ had an abundance of epifauna $121 \mathrm{ind} / \mathrm{m}^{2}$, medium density (station B) by the number of stands 333 ind $/ \mathrm{m}^{2}$ the abundance of epifauna 93 ind $/ \mathrm{m}^{2}$, and precision rarely (station C) by the number of stands $308 \mathrm{ind} / \mathrm{m}^{2}$, has an abundance of epifauna $67 \mathrm{ind} / \mathrm{m}^{2}$. The correlation values between the density of seagrass with the abundance of epifauna have a value of correlation coefficient $r=0,949$ with the value $\alpha<0.05$ indicates that there is a positive and high correlation.

Keywords $\quad$ : Seagrass Ecosystem, Epifauna's Abundance, Pari Island.

*)Penulis penanggungjawab 


\section{PENDAHULUAN}

Pulau Pari secara administratif merupakan salah satu kelurahan di Kecamatan Kepulauan Seribu Selatan, Kabupaten Kepulauan Seribu, Provinsi DKI Jakarta.Pulau Pari sendiri memiliki ekosistem laut yang lengkap, yaitu ekosistem terumbu karang, ekosistem lamun, dan ekosistem mangrove.Dari ketiga ekosistem tersebut, ekosistem lamun menjadi salah satu ekosistem yang mendominasi karena hampir terdapat pada sepanjang garis pantainya. Ekosistem lamun merupakan suatu ekosistem yang sangat penting keberadaanya karena memiliki keanekaragaman hayati tinggi, ekosistem ini menjadi habitat yang baik bagi beberapa biota laut, seperti epifauna

Epifauna merupakan salah satu biota yang hidup pada daerah ekosistem lamun baik pada dasar maupun pada daun lamun.Keberadaan ekosistem lamun sangat mempengaruhi keberadaan dan kehidupan dari epifauna ini.Ekosistem ini menunjang kehidupan epifauna sebagai sumber makanan alami yang terdapat pada daun berupa perifiton dan serasah lamun, selain itu ekosistem ini merupakan tempat berlindung bagi epifauna dari berbagai macam gangguan, baik gangguan dari alam maupun aktivitas manusia, predator, dan kompetisi dalam mencari makanan dan habitat.Selain itu faktor lingkungan dari kondisi ekosistem lamun dan perairan itu sendiri sangat berpengaruh terhadap kelimpahan epifauna. Menurut Prakoso (2015), kondisi parameter lingkungan yang mempengaruhi kelimpahan epifauna di lamun yaitu suhu, salinitas, arus, kecerahan, kedalaman, $\mathrm{pH}$, dan DO (Dissolved Oxygen), dan TSS (Total Suspended Solid), selain dipengaruhi faktor tersebut, faktor yang mempengaruhi tumbuh hidupnya lamun dapat juga dipengaruhi oleh faktor predasi yang memanfaatkan epifauna dan lamun sebagai sumber makanan dan juga adanya kompetisi atau saingan dalam mencari habitat dan makanan bagi epifauna tersebut sehingga menyebabkan perubahan distribusi lamun dan epifauna.

Tujuan dilakukannya penelitian ini adalah untuk mengetahui:

1. Mengetahui jenis lamun di Pantai Lipi, Pulau Pari, Kepulauan Seribu;

2. Mengetahui kelimpahan epifauna pada tingkat kerapatan lamun yang berbeda di Pantai Lipi, Pulau Pari, Kepulauan Seribu;

3. Mengetahui hubungan perbedaan kerapatan lamun dengan kelimpahan epifauna di Pantai Lipi, Pulau Pari, Kepulauan Seribu.

\section{MATERI DAN METODE PENELITIAN}

\section{A. Materi Penelitian}

Materi yang dikaji dalam penelitian ini adalah ekosistem lamun dengan tingkat kerapatan yang berbeda, dan sampel epifauna yang diperoleh dari perairan di Pantai Lipi, Pulau Pari, Kepulauan Seribu. Peralatan yang digunakan dalam penelitian ini adalah GPS (Global Positioning System) dengan ketelitian $1^{\circ}$ untuk memploting lokasi sampling, line transek sepanjang 50 meter untuk menandai lokasi penutupan, kuadran transek seluas $1 \times 1 \mathrm{~m}$ sebagai batas pengamatan lamun, secchi disc dengan ketelitian $1 \mathrm{~cm}$ untuk mengukur kecerahan dan kedalaman, bola arus dengan tali sepanjang $1 \mathrm{~m}$ dan stopwatch dengan ketelitian $1 \mathrm{~m} /$ detik untuk mengukur arus, refraktometer dengan ketelitian $1 \%$ o untuk mengukur salinitas, termometer dengan ketelitian $1{ }^{\circ} \mathrm{C}$ untuk mengukur suhu air, kertas indikator $\mathrm{pH}$ untuk mengukur nilai $\mathrm{pH}$, kamera underwater untuk dokumentasi, gelas ukur $50 \mathrm{ml}$ dengan ketelitian $1 \mathrm{ml}$ untuk pengukuran oksigen terlarut (DO) dan bahan organik total, erlenmeyer $500 \mathrm{ml}$ untuk melakukan melakukan titrasi oksigen terlarut (DO) dan pengukuran bahan organik total, botol BOD Winkler $250 \mathrm{ml}$ untuk mengambil air sampel dalam pengukuran kadar oksigen terlarut (DO), buret dan hotplate untuk melakukan pengukuran bahan organik total, botol sampel $1000 \mathrm{ml}$ untuk mengambil air sampel, kertas saring, corong, dan oven untuk melakukan uji TSS (Total Suspended Solid), pipet tetes dan spuit suntik untuk mengambil reagen, botol reagen sebagai wadah reagen, botol untuk wadah sampel biota, masker dan snorkel untuk membantu pengamatan di lapangan, alat tulis untuk pencatatan data, kaca pembesar untuk mengamati jenis epifauna yang diperoleh dan buku identifikasi (FAO Species Identification Guide for Fishery Purpose tahun 2002) dan internet untuk checklist jenis epifauna yang diperoleh, dan seagrass speccies codes (Marine Plant Ecology Group Northerm Fisheries Centre, 2003) untuk checklist jenis lamun. Bahan yang digunakan dalam penelitian ini adalah formalin $4 \%$ untuk mengawetkan sampel epifauna, aquades untuk kalibrasi alat titrasi dan refraktometer. $\mathrm{MnSO}_{4}$ (Mangan sulfat), $\mathrm{NaOH}$ dalam KI, Amilum. $\mathrm{Na}_{2} \mathrm{~S}_{2} \mathrm{O}_{3}$ (Natrium tiosulfat), dan $\mathrm{H}_{2} \mathrm{SO}_{4}$ untuk titrasi kandungan $\mathrm{O}_{2}$ terlarut dalam air (DO). Air sampel, $\mathrm{KMnO}_{4}, \mathrm{H}_{2} \mathrm{SO}_{4}$, dan Naoxalate untuk pengukuran bahan organik total.

\section{B. Metoda Penelitian}

Metode penelitian yang digunakan adalah metode survei.Sedangkan metode pengambilan sampel epifauna menggunakan metode purposive sampling, yaitu pengambilan sampel secara sengaja, sesuai dengan persyaratan sampel yang diperlukan dengan asumsi bahwa sampel yang diambil dapat mewakili populasi dari lokasi penelitian. Menurut Notoatmodjo (2002), metode purposive sampling yaitu penentuan lokasi dengan beberapa pertimbangan tertentu oleh peneliti, berdasarkan ciri atau sifat-sifat populasi yang sudah diketahui sebelumnya. 


\section{Metoda Sampling}

Sampling yang dilakukan dalam penelitian ini meliputi:

1. Pengamatan dan pengukuran kerapatan lamun;

2. Pengambilan sampel epifauna;

3. Pengukuran paremeter fisika;

4. Pengukuran parameter kimia.

Pengambilan sampel dilakukan pada 3 titik stasiun dengan kerapatan lamun yang berbeda (padat, sedang, jarang) dengan luasan yang sama $(5 \mathrm{~m}$ x $5 \mathrm{~m})$ pada setiap stasiun. Sampel epifauna yang didaptkan kemudian dihitung jumlahnya, kemudian diamati menggunakan kaca pembesar diamati warna dan bentuk cangkangnya untuk dilakukan identifikasi.Identifikasi sampel epifana dilakukan dengan menggunakan buku (FAO Species Identification Guide for Fishery Purpose).Lalu dilakukan analisis data dan uji regresi.

\section{Analisa Data}

\section{a. Kelimpahan relatif $(\mathbf{K R})$}

Kelimpahan relatif adalah nilai antara kelimpahan individu tiap jenis dengan seluruh individu dalam suatu komunitas. Menurut Odum (1993), kelimpahan relatif dihitung dengan rumus Shannon-Wiener:

Keterangan:

$$
\mathrm{KR}=\frac{m i}{N} \times 100 \%
$$

$\mathrm{KR}=$ kelimpahan relatif

$\mathrm{ni}=$ jumlah individu spesies ke-i

$\mathrm{N}=$ jumlah individu seluruh spesies

b. Indeks keanekaragaman, keseragaman, dan dominasi

\section{- Indeks keanekaragaman}

Indeks keanekaragaman dapat dihitung dengan menggunakan Indeks Shannon-Wiener:

$p^{i}=\frac{\pi i}{N}$

Keterangan:

H' = indeks keanekargaman Shanon-Wiener

$\mathrm{Pi} \quad=$ perbandingan jumlah individu ke-I dengan jumlah total individu $(\mathrm{ni} / \mathrm{N})$

$\mathrm{ni} \quad=$ jumlah individu suatu jenis

$\mathrm{N} \quad=$ jumlah individu seluruh jenis

Kisaran indeks keanekaragaman dapat diklasifikasikan sebagai berikut (Ferianita, 2007)::

$\mathrm{H}^{\prime}<1 \quad$ : Komunitas biota tidak stabil

$1<\mathrm{H}^{\prime}<3$ : Stabilitas komunitas biota sedang

H'>3 : Stabilitas komunitas biota dalam kondisi prima (stabil)

\section{- Indeks keseragaman}

Menurut Odum (1993), keseragaman jenis yaitu komposisi tiap spesies yang terdapat dalam komunitas. Keseragaman jenis tersebut didapat dengan membandingkan indeks keanekaragamannya dengan nilai maksimumnya, dengan menggunakan rumus sebagai berikut:

$=\frac{\mathrm{H}^{\mathrm{T}}}{\mathrm{H} \text { maks }}$

Keterangan:

$\mathrm{H}^{\prime} \quad=$ indeks Keanekaragaman

e $\quad=$ indeks Keseragaman

$\mathrm{H}$ maks $=$ jumlah seluruh jenis $(\ln \mathrm{S})$

$\mathrm{S} \quad=$ jumlah spesies

Dimana menurut Krebs (1999), indeks keseragaman dapat diklasifikasikan sebagai berikut:

$0,6-1 \quad$ : Tingkat keseragaman populasi tinggi

$0,4-0,6 \quad$ : Tingkat keseragaman populasi sedang

$0-0,4 \quad$ : Tingkat keseragaman populasi rendah

\section{- Indeks dominas}

Menurut Odum (1993), nilai indeks dominasi digunakan untuk mengkaji adanya dominasi oleh suatu spesies tertentu di dalam suatu ekosistem. Dominasi spesies yang cukup besar akan mengarah pada kondisi ekosistem atau komunitas yang labil atau tertekan, rumus yang digunakan adalah:

Keterangan:

$$
\mathrm{D}=\sum\left(\frac{\mathrm{ni}}{\mathrm{N}}\right)^{2}
$$

$\mathrm{D}=$ indeks dominasi

$\mathrm{Ni}=$ jumlah individu dalam spesies

$\mathrm{N}=$ jumlah total individu

${ }^{\text {C }}$ Copyright by Management of Aquatic Resources (MAQUARES) 
Kriteria indeks dominasi menurut Odum, (1993):

$0<\mathrm{D} \leq 0,5 \quad$ : Tidak ada spesies/ genus yang mendominasi

$0,5<\mathrm{D}<1 \quad$ : Terdapat spesies/ genus yang mendominasi

\section{HASIL DAN PEMBAHASAN}

\section{A. Hasil} Tabel 1.

Hasil Kerapatan Lamun (ind $/ \mathrm{m}^{2}$ ) pada Perairan Pantai Lipi Pulau Pari Kepulauan Seribu yaitu tersaji pada

Tabel 1. Komposisi Jenis Lamun pada Kerapatan (Padat, Sedang dan Jarang)

\begin{tabular}{|c|c|c|c|c|c|c|c|}
\hline \multirow{3}{*}{ No } & \multirow{3}{*}{ Jenis } & \multicolumn{6}{|c|}{ Kerapatan Lamun } \\
\hline & & \multicolumn{2}{|c|}{ A (Padat) } & \multicolumn{2}{|c|}{ B (Sedang) } & \multicolumn{2}{|c|}{ C (Jarang) } \\
\hline & & ni & KR $(\%)$ & ni & $\operatorname{KR}(\%)$ & $\mathrm{Ni}$ & KR $(\%)$ \\
\hline 1 & Thalassia sp. & 399 & 100 & 324 & 97,30 & 304 & 99 \\
\hline 2 & Enhalus sp. & - & - & 7 & 2,10 & 4 & 1 \\
\hline 3 & Cymodocea sp. & - & - & 2 & 0,60 & - & - \\
\hline & umlah (ind/m²) & 399 & 100 & 333 & 100 & 308 & 100 \\
\hline
\end{tabular}

Hasil pengukuran parameter lingkungan kualitas air fisika dan kimia yang tersaji pada Tabel 2.

Tabel 2. Parameter Lingkungan

\begin{tabular}{|c|c|c|c|c|}
\hline \multirow{2}{*}{$\begin{array}{c}\text { Parameter } \\
\text { Lingkungan }\end{array}$} & \multicolumn{3}{|c|}{ Kerapatan Lamun } & \multirow{2}{*}{$\begin{array}{l}\text { Nilai Optimum } \\
\text { Menurut Pustaka }\end{array}$} \\
\hline & A (Padat) & B (Sedang) & C (Jarang) & \\
\hline Suhu Air $\left({ }^{\circ} \mathrm{C}\right)$ & 30 & 30 & 30 & 28 - 30 (Sumatrin, 2015) \\
\hline Kedalaman (m) & $0,45-0,66$ & $0,47-1,2$ & $0,44-0,6$ & $1-10$ (Nybakken, 2005) \\
\hline Kecerahan $(\mathrm{m})$ & sampai dasar & sampai dasar & sampai dasar & Sampai dasar (Tuwo, 2011) \\
\hline Kec. Arus $(\mathrm{m} / \mathrm{s})$ & $0,03-0,14$ & $0,09-0,1$ & $0,02-0,04$ & 0,5 (Dahuri, 2003) \\
\hline Salinitas $(\% o)$ & $30-34$ & $30-34$ & $30-33$ & 25 - 35 (Supriharyono,2009) \\
\hline $\mathrm{TSS}(\mathrm{mg} / \mathrm{l})$ & 19 & 15 & $<8$ & < 400 (Alongi, 1998) \\
\hline $\mathrm{pH}$ & 8 & 8 & 8 & $7,3-9,0$ (Sumatrin, 2015) \\
\hline $\mathrm{DO}(\mathrm{mg} / \mathrm{l})$ & $3,4-3,8$ & $3,4-4,0$ & $3,4-4,0$ & 3,5-4,0 (Hutabarat, 2000) \\
\hline Bahan Organik Total (mg/l) & 2,80 & 2,20 & 2,00 & $\begin{array}{l}20 \text { (Kepmen LH Nomor } 51 \\
\text { Tahun } 2004 \text { lampiran III) }\end{array}$ \\
\hline
\end{tabular}


Hasil komposisi dan kelimpahan epifauna pada lokasi penelitian yang tersaji pada Tabel 2.

$\underline{\text { Tabel 2. Komposisi dan Kelimpahan Relatif Epifauna pada Tiga Kerapatan Lamun }}$

\begin{tabular}{|c|c|c|c|c|c|c|c|}
\hline \multirow{3}{*}{ No } & \multirow{3}{*}{ Jenis } & \multicolumn{6}{|c|}{ Kerapatan Lamun } \\
\hline & & \multicolumn{2}{|c|}{ Padat (A) } & \multicolumn{2}{|c|}{ Sedang (B) } & \multicolumn{2}{|c|}{ Jarang (C) } \\
\hline & & ni & KR $(\%)$ & ni & KR $(\%)$ & ni & KR $(\%)$ \\
\hline & Echinodermata & & & & & & \\
\hline 1 & Holoturia leucospilota & 3 & 2,48 & - & - & 5 & 7 \\
\hline \multirow[t]{2}{*}{2} & Archaster typicus & 2 & 1,65 & 1 & 1,08 & - & - \\
\hline & Bivalvia & & & & & & \\
\hline 3 & Gafrarium sp. & 7 & 5,79 & 2 & 2,15 & 2 & 3 \\
\hline 4 & Barbatia sp. & 2 & 1,65 & 2 & 2,15 & 1 & 1 \\
\hline 5 & Telina sp. & 5 & 4,13 & 3 & 3,23 & - & - \\
\hline 6 & Circe sp. & 6 & 4,96 & 7 & 7,53 & 3 & 4 \\
\hline 7 & Paphia sp. & 2 & 1,65 & 1 & 1,08 & - & - \\
\hline 8 & Mactra sp. & 1 & 0,83 & 2 & 2,15 & 2 & 3 \\
\hline \multirow[t]{2}{*}{9} & Fragum sp. & 2 & 1,65 & - & - & 1 & 1 \\
\hline & Gastropoda & & & & & & \\
\hline 10 & Pyrene sp. & - & - & - & - & 2 & 3 \\
\hline 11 & Parametaria sp. & - & - & 1 & 1,08 & 6 & 9 \\
\hline 12 & Euplica sp. & 9 & 7,44 & 12 & 12,90 & 19 & 28 \\
\hline 13 & Clypeomorus sp. & 19 & 15,70 & 16 & 17,20 & 9 & 13 \\
\hline 14 & Solenosteira sp. & 5 & 4,13 & 3 & 3,23 & - & - \\
\hline 15 & Nerita sp. & 4 & 3,31 & 1 & 1,08 & 1 & 1 \\
\hline 16 & Rhinocalvis sp. & 8 & 6,61 & 8 & 8,60 & - & - \\
\hline 17 & Strombus sp. & 28 & 23,14 & 20 & 21,51 & 11 & 16 \\
\hline 18 & Batilaria sp. & 17 & 14,05 & 14 & 15,05 & 4 & 6 \\
\hline 19 & Ranularia sp. & - & - & - & - & 1 & 1 \\
\hline \multirow[t]{2}{*}{20} & Morula sp. & 1 & 0,83 & - & - & - & - \\
\hline & Jumlah (ind $/ \mathbf{m}^{2}$ ) & 121 & 100 & 93 & 100 & 67 & 100 \\
\hline
\end{tabular}

Kelimpahan epifauna berdasarkan kerapatan lamun padat, sedang dan jarang jenis yang didapatkan yaitu kelas Echinodermata sebanyak 2 genera, Bivalvia sebanyak 7 genera dan gastropoda sebanyak 11 genera yang tersaji pada Gambar 1.

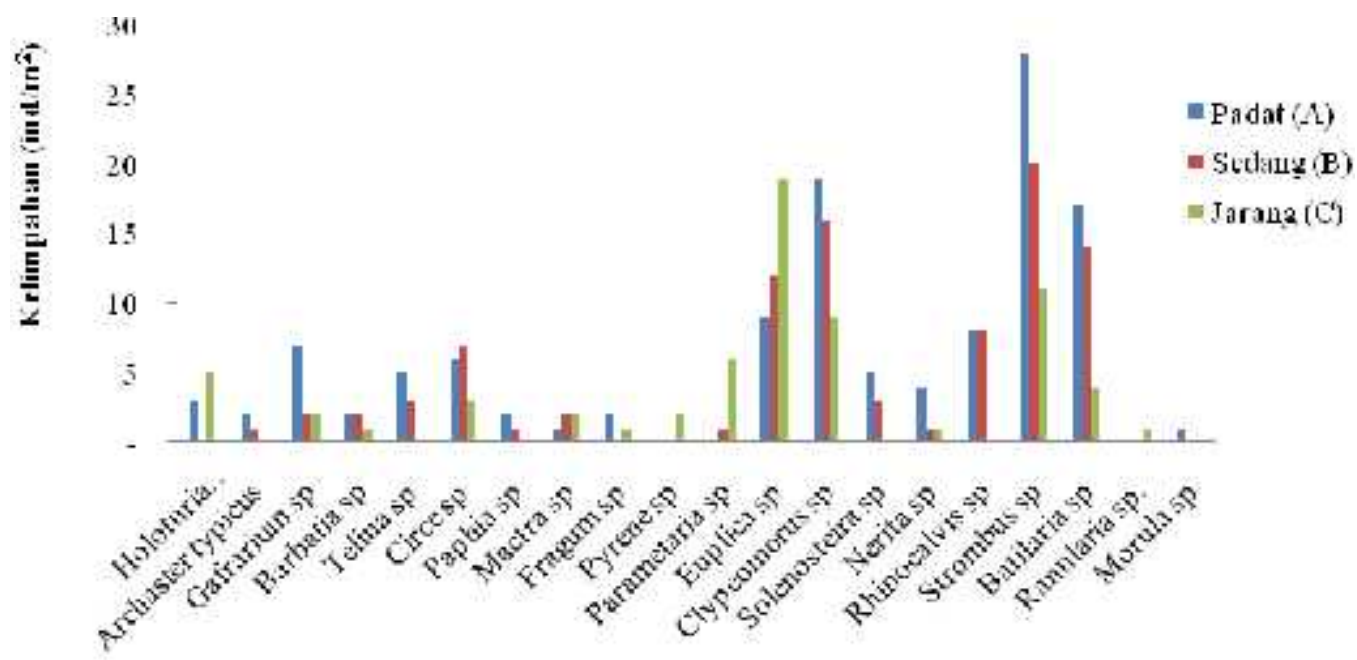

Jemis Epifauma

${ }^{\circledR}$ Copyright by Management of Aquatic Resources (MAQUARES) 
Gambar 1. Histogram Kelimpahan Epifauna (Ind/m2) pada Tiga Kerapatan Lamun

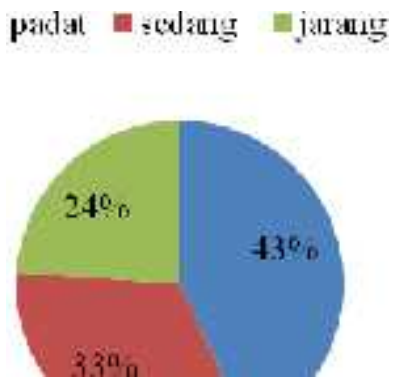

Gambar 2. Diagram Kelimpahan Epifauna Berdasarkan Kerapatan Lamun

Berdasarkan hasil yang didapatkan menggunakan uji analisis korelasi Pearson dengan bantuan SPSS, untuk mengetahui hubungan kerapatan lamun dengan kelimpahan epifauna dengan hasil sebagai berikutdapat dilihat pada Tabel 3 :

Tabel 4. Hasil Korelasi Pearson antara Kerapatan Lamun dengan Kelimpahan Epifauna

\begin{tabular}{ccc}
\hline Analisa Uji & r & Sig. (2-tailed) \\
\hline Kerapatan Lamun dengan Kelimpahan Epifauna & 0,949 & $0,000^{* *}$ \\
\hline
\end{tabular}

\section{B. Pembahasan}

Perairan Pulau Pari memiliki ekosistem padang lamun yang cukup baik. Selain itu terdapat tiga tingkat kerapatan lamun yang berbeda yaitu tingkat kerapatan padat, sedang, dan jarang. Jenis-jenis lamun yang dijumpai di perairan ini adalah Thalassia sp., Enhalus sp., dan Cymodocea sp. Jenis lamun yang paling mendominasi pada lokasi penelitian adalah Thalassia sp., dimana keberadaannya hampir terdapat di setiap stasiun dan kondisi dari lamun tersebut.Pada lokasi stasiun A dan B memiliki tingkat kerapatan lamun yang padat dan sedang dengan jumlah kerapatan berkisar 333-399 ind $/ \mathrm{m}^{2}$. Stasiun C memiliki jumlah kerapatan 308 ind $/ \mathrm{m}^{2}$ yang dapat dikatakan sebagai kerapatan yang jarang dibandingkan dengan stasiun A dan B. Lokasi stasiun $\mathrm{C}$ berada pada bagian utara Pantai Lipi. Tidak jauh dari lokasi sampling pada stasiun $\mathrm{C}$ terdapat aktivitas pembangunan resort yang dilakukan pada Pulau Tengah di seberang Pulau Pari yang menjadikan kualitas perairan tersebut kurang baik untuk pertumbuhan lamun karena adanya aktifitas pembuangan limbah dan pariwisata. Menurut Feryatun (2012), penyebaran lamun memang sangat bervariasi tergantung pada topografi pantai dan pola arus pasang surut. Penutupan lamun yang rendah dapat ditemui pada daerah yang telah terganggu aktivitas manusia dan pada daerah alami mengalami penutupan yang tinggi.

Kandungan oksigen terlarut yang diukur pada setiap stasiun cukup stabil dengan nilai berkisar 3,4-4,0 $\mathrm{mg} / \mathrm{l}$. Kandungan oksigen terlarut sangat dibutuhkan oleh biota dan oksigen terlarut yang tinggi disebabkan oleh arus karena proses pengadukan. Menurut Pescod (1973) dalam Pamuji (2015), kandungan oksigen terlalut yang baik adalah diatas $2 \mathrm{mg} / \mathrm{l}$ bagi biota perairan.Epifauna yang ditemukan saat sampling pada perairan Pantai Lipi berjumlah 281 individu dan berhasil teridentifikasi menjadi 18 genera dan 2 spesies, terbagi atas kelas Echinodermata, gastropoda, dan bivalvia. Berdasarkan Tabel 2 epifauna yang ditemukan pada lokasi dari hasil 3 kali sampling diperoleh $121 \mathrm{ind} / \mathrm{m}^{2}$ dikerapatan padat, $93 \mathrm{ind} / \mathrm{m}^{2}$ dikerapatan sedang, dan $67 \mathrm{ind} / \mathrm{m}^{2}$ dikerapatan jarang. Epifauna yang paling banyak ditemukan adalah jenis Clypeomorus sp. dan Strombus sp. Jumlah epifauna terbesar ditemukan pada stasiun dengan kerapatan lamun yang padat.Hal ini sesuai dengan pendapat Hutomo (1985) dalam Metungun et al., (2011), kepadatan lamun yang tinggi memungkinkan epifauna untuk mendapatkan tempat perlindungan dan mampu memberikan ketersediaan berbagai sumber makanan dan stabilitas lingkungan yang dapat menenangkan arus dan gelombang menyebabkan perairan sekitar menjadi lebih tenang sehingga partikel mineral maupun organik yang tersisa di perairan dengan mudah mengendap di daerah padang lamun, menjadikan padang lamun merupakan lingkungan yang sangat baik untuk kehidupan epifauna. Menurut Ruswahyuni (2008), kerapatan lamun yang jarang mengakibatkan epifauna tidak terlindung dari predator dan tidak memberikan ketersedian makanan yang cukup.Berdasarkan nilai yang didapatkan dari Total Suspend Solid (TSS) pada stasiun A (Padat) sebesar $19 \mathrm{mg} / \mathrm{l}$, stasiun B (sedang) sebesar $15 \mathrm{mg} / \mathrm{l}$ dan stasiun C (jarang) sebesar $<8 \mathrm{mg} / \mathrm{l}$. Nilai TSS berasal dari senyawa organik dan anorganik, nilai TSS yang tinggi dapat di sebabkan oleh adanya biota, karena biota perairan akan meningkatkan kadar amoniak dan Kandungan bahan organik total yang didapatkan setiap stasiunnya yaitu sebesar 2,8 mg/l, 2,2 mg/l, dan 2,0 mg/l pada masing-

\footnotetext{
(c) Copyright by Management of Aquatic Resources (MAQUARES)
} 
masing kerapatan padat, sedang dan jarang. Bahan organik sangat dibutuhkan oleh epifauna sebagai sumber makanan.Bahan organik ini bisa dihasilkan dari hasil dekomposisi dari tumbuhan seperti serasah daun lamun. Menurut Zulkifli et al., (2009), kandungan bahan organik yang tinggi akan mempengaruhi tingkat keseimbangan perairan. Tingginya kandungan bahan organik akan mempengaruhi kelimpahan organisme, dimana terdapat organisme-organisme tertentu yang tahan terhadap tingginya kandungan bahan organik.

Hasil dari uji korelasi Pearson antara kerapatan lamun dengan kelimpahan epifauna memiliki nilai korelasi (r) sebesar 0,949.Nilai korelasi yang didapatkan pada hubungan kerapatan lamun dengan kelimpahan epifauna memiliki korelasi yang kuat.Hal ini diperkuat oleh Arifin (2005) dalam Rukim (2006), bahwa keeratan hubungan antar variabel dengan nilai $0,70 \leq \mathrm{r} \leq 1,00$ menunjukkan adanya hubungan yang tinggi. Adanya nilai korelasi yang positif terjadi pada kerapatan lamun dengan kelimpahan epifaunamenyatakan bahwa hubungan yang terjadi searah, yaitu apabila kerapatan lamun meningkat maka akan diikuti meningkatnya kelimpahan epifauna dan sebaliknya. Ekosistem lamun menjadi habitat yang baik bagi epifauna.Faktor yang sangat mempengaruhi keberadaan epifauna adalah ketersedian nutrient di perairan dan kandungan bahan organik dengan sifat epifauna yang hidup menempel pada daun lamun atau berada pada permukaan dasar perairan.Hal ini diperkuat oleh Ferianita (2007), epifauna merupakan biota bentos yang hidup pada permukaan substrat atau dasar laut.Selain itu lebatnya daun lamun yang mampu meredam arus dan gelombang dapat mempengaruhi keberadaan dari epifauna, sehingga banyak organisme yang menjadikan ekosistem lamun dengan kerapatan padat sebagai tempat perlindungan dan tempat mencari makan dimana pada lokasi ini dapat menyediakan banyak makanan bagi epifauna.

\section{KESIMPULAN}

Berdasarkan hasil penelitian yang telah dilakukan, dapat disimpulkan bahwa:

1. Jenis lamun yang ada di perairan Pantai Lipi yaitu terdapat tiga jenis lamun diantaranya Thalassia sp., Enhalus sp. dan Cymodocea sp;

2. Kelimpahan epifauna yang didapat berdasarkan tingkat kerapatan lamun di perairan Pantai Lipi yaitu pada kerapatan lamun yang padat (stasiun A) dengan jumlah tegakan $399 \mathrm{ind} / \mathrm{m}^{2}$ memiliki kelimpahan epifauna $121 \mathrm{ind} / \mathrm{m}^{2}$. Kerapatan sedang (stasiun B) dengan jumlah tegakan $333 \mathrm{ind} / \mathrm{m}^{2}$ memiliki kelimpahan epifauna sebanyak $93 \mathrm{ind} / \mathrm{m}^{2}$ dan pada kerapatan jarang (stasiun C) dengan jumlah tegakan $308 \mathrm{ind} / \mathrm{m}^{2}$, memiliki kelimpahan epifauna sebanyak $67 \mathrm{ind} / \mathrm{m}^{2}$;

3. Hubungan antara kerapatan lamun dengan kelimpahan epifauna di perairan Pantai Lipi, Pulau Pari, Kepulauan Sertibu menunjukan adanya nilai korelasi yang positif dan kuat memiliki nilai korelasi (r) sebesar 0,949 dengan signifikasi $\alpha<0,05$. yang artinya setiap peningkatan jumlah kerapatan lamun maka akan diikuti oleh peningkatan jumlah kelimpahan epifauna di perairan pantai Lipi, Pulau Pari, Kepulauan Seribu.

\section{UCAPAN TERIMAKASIH}

Ucapan terimakasih ditujukan kepada Dra. Niniek Widyorini, MS., Ir. Anhar Solichin, M.Si., Drs. Ign. Boedi Hendrarto,MSc, Ph.D., Dr. Ir. Pujiono Wahyu P., MS., yang telah memberikan masukan, kritik dan saran yang sangat berarti bagi penulis.

\section{DAFTAR PUSTAKA}

Ferianita, F. M. 2007. Metode Sampling Bioekologi. Bumi Aksara. Jakarta.

Feryatun, Fiki., B. Hendrarto, N. Widyorini. 2012. Kerapatan dan Distribusi Lamun (Seagrass) Berdasarkan Zona Kegiatan yang Berbeda di Perairan Pulau Pramuka, Kepulauan Seribu. Jurnal Sumberdaya Perairan.

Krebs, C. J. 1999. Ecological Method.An Imprint of Addison Wesley Longman, Inc, Columbia.636 hlm.

Metungun, J., Juliana dan Y. Mariana. 2011. Kelimpahan Gastropoda pada Habitat Lamun di Perairan Teluk Un Maluku Tenggara. Program Studi Budidaya Perairan. Politeknik Perikanan Negri Tual.

Notoatmodjo, S. 2002. Metodologi Penelitian Kesehatan. Rineka Cipta, Jakarta, 208 hlm.

Odum, P. E. 1993. Dasar-dasar Ekologi : Alih Bahasa Tjahjono Samingan. Edisi Ketiga Universitas Gajah Mada. Yogyakarta.

Pamuji.A., M. R. Muskananfola dan Churun A’in.2015. Pengaruh Sedimentasi Terhadap Kelimpahan Makrozoobentos di Muara Sungai Betahwalang Kabupaten Demak. Jurnal Saintek Perikanan., 10(2):129-135.

\footnotetext{
${ }^{\circledR}$ Copyright by Management of Aquatic Resources (MAQUARES)
} 
Prakoso, Kukuh., Supriharyono dan Ruswahyuni. 2015. Kelimpahan Epifauna di Substrat Dasar dan Daun Lamun Dengan Kerapatan yang Berbeda di Pulau Pahawang Provinsi Lampung. Diponegoro Journal of Maquares., 4(3):117-122.

Rukim, Usep. 2006. Analisa Kelimpahan dan Komposisi Ikan Demersal pada Tingkat Kerapatan Lamun yang Berbeda di Perairan Pantai Pulau Panjang Jepara.[Skripsi]. Jurusan Perikanan. Universitas Diponegoro.

Ruswahyuni. 2008. Hubungan antara Kelimpahan Meiofauna dengan Tingkatan Kerapatan Lamun yang Berbeda di Pantai Pulau Panjang Jepara. Universitas Diponegoro. Semarang.

Zulkifli, H., Z. Hanafiah., D. A. Puspitawati. 2009. Struktur dan Fungsi Komunitas Makrozoobenthos di Perairan Sungai Musi Kota Palembang: Telaah Indikator Pencemaran Air. Jurusan FMIPA. Universitas Sriwijaya. 